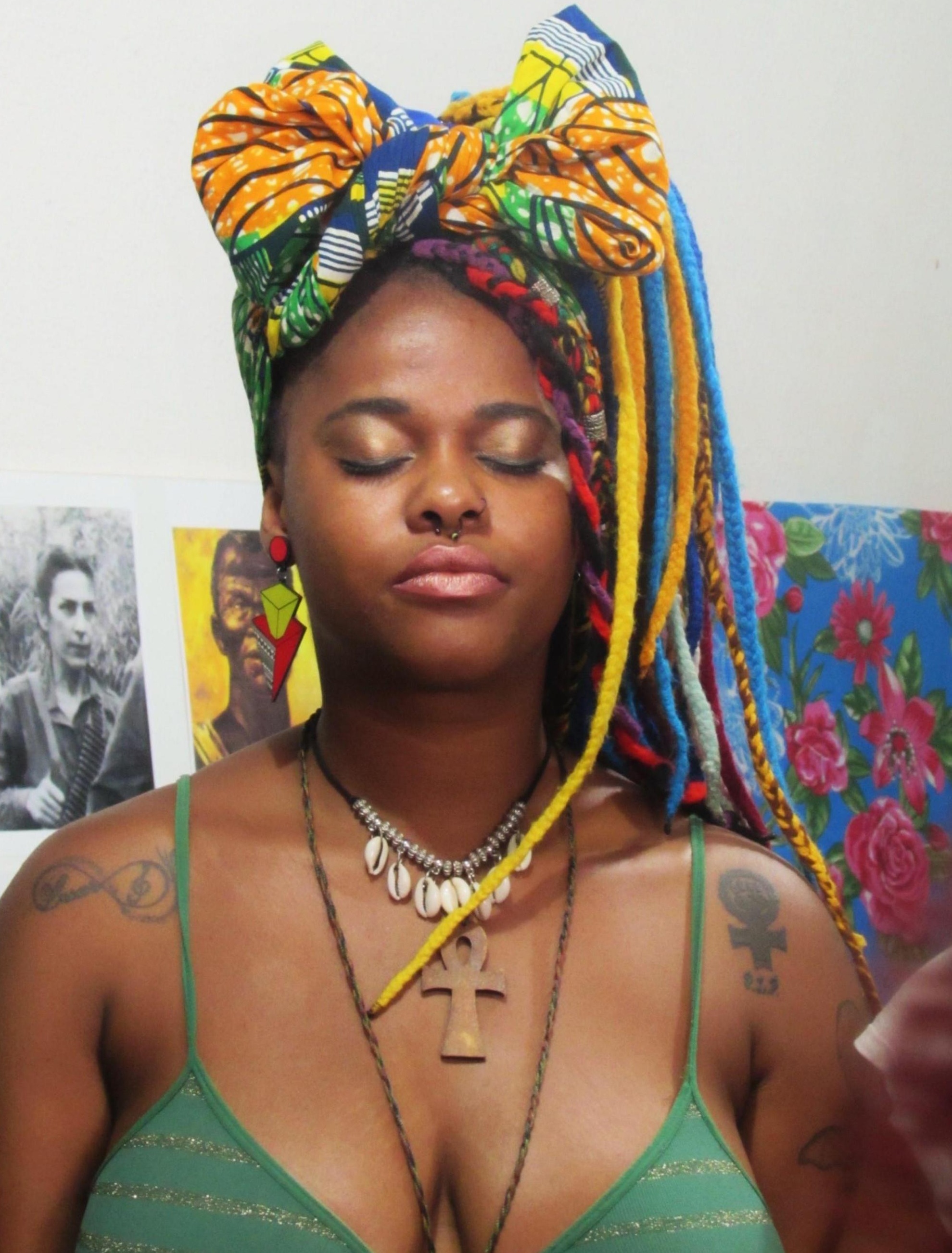




\section{Acessibilidade para Pessoas com Deficiência Visual: um Levantamento Preliminar nos Setores Hoteleiros Sul e Norte de Brasília}

Accessibility for People with Visual Impairment: a Preliminary Survey in Sectors Hotel Sectors South and North of Brasília

Donária Coelho Duarte ${ }^{1}$

Jéssika Carvalho Ricardo Pereira²

\footnotetext{
${ }^{1}$ Possui graduação em Ciências da Administração pela Universidade Federal de Santa Catarina (1995), mestrado em Engenharia de Produção pela Universidade Federal de Santa Catarina (1998) e doutorado em Engenharia de Produção pela Universidade Federal de Santa Catarina (2005). Atualmente é Professora Adjunta da Universidade de Brasília onde leciona na graduação no Curso Gestão de Agronegócios UnB - Unidade Planaltina e no Mestrado do Centro de Excelência em Turismo (CET). É membro do Laboratório de Estudos de Turismo e Sustentabilidade do Centro de Desenvolvimento Sustentável (Lets/UnB) e membro do Grupo de Pesquisa Produção, Consumo, Turismo e Sustentabilidade do Centro de Desenvolvimento Sustentável da UnB (CDS//UnB - Diretório de Grupos de Pesquisa/CNPq). Coordena o Núcleo de Estudos sobre Turismo Responsável, Acessível e Sênior (Netras - All). Sua área de atuação inclui os seguintes temas: turismo acessível, turismo sênior e turismo responsável.E-mail: donaria@hotmail.com
}

${ }^{2}$ E-mail: jessika.carvalhorp@gmail.com 


\section{Resumo}

Este artigo tem o objetivo de analisar a acessibilidade para pessoas com deficiência visual no setor hoteleiro. Para tanto, foi realizada uma pesquisa bibliográfica sobre as peculiaridades da deficiência visual e o turismo para essas pessoas. O estudo se caracteriza como exploratório, onde empregouse um roteiro de entrevista e um roteiro de observação, ambos aplicados em 30 hotéis localizados nos setores norte e sul de Brasília. A coleta de dados contou com a colaboração do presidente da Associação de Amigos dos Deficientes Visuais de Brasília, permitindo uma análise mais profunda. O levantamento conclui que a maioria dos hotéis não era acessível para deficientes visuais e os funcionários destes não receberam treinamento para atender essas pessoas. Constatou-se também que os estabelecimentos investigados não receberam a visita de um órgão fiscalizador, o que leva a reflexão de que a falta de fiscalização pode acarretar no descumprimento das leis e normas.

Palavras-chave: Brasília, Hotelaria, Deficiência Visual, Acessibilidade.

\section{Abstract}

This article has the objective analyze the accessibility for people with visual disabilities in the hotel sector. Therefore, it was made a bibliographic research about the peculiarities of visual disabilitie and tourism to these people. The study is characterized as exploratory, in which we used an interview guide and a observation script, both applied in 30 hotels located in the sectors north and south of Brasilia. The data collection had the collaboration of the President of the Friends Association of the Visually Impaired of Brasilia, allowing a deeper analysis. The survey concludes that the majority of hotels was not accessible to people with visual disabilities and their employees were not trained to receive these people. It was also verified that the establishments investigated did not receive the visit of a control organ, which leads to the reflection that the lack of inspection can cause in the noncompliance with the laws and norms.

Keywords: Brasília, Hotel, Visual Disabilities. Accessibility.

\section{Introdução}

Em pleno século 21, com a evolução da informação e o acesso a várias tecnologias, a acessibilidade já deveria ser um pressuposto em todos os setores e, inclusive, no turismo. Entretanto, tendo em vista vários fatores e, dentre esses, o fato da legislação no país se r relativamente re ce n t e (por exemplo, a Norma NBR 9050 data de 2004), o tema torna-se relevante e merece atenção. Corroborando, constata-se que, com a facilidade de circulação da informação, as pessoas estão cada vez mais conhecedoras de seus direitos e os pleiteiam. Da mesma forma, nota-se que a sociedade está mais exigente no tocante a uma postura ética das empresas, emanando uma atuação cada vez mais responsável e consciente. É nesse contexto que o tema acessibilidade aplicado ao turismo se torna relevante.

O Censo Demográfico realizado pelo IBGE em 2010 revelou que até aquele ano, cerca de 23,9\% da população brasileira (mais de 45,6 milhões de pessoas) possuía algum tipo de deficiência. 0 mesmo Censo apontou que entre os diferentes tipos de deficiência, a deficiência visual era a que mais afetava a população (aproximadamente 35,8 milhões de pessoas). Tal dado revela a necessidade de que todos os empreendimentos busquem meios de se preparar para suprir as 
demandas desses clientes. Desta forma, torna-se relevante, portanto, a realização de pesquisas e trabalhos que discutam a questão da acessibilidade, sobremaneira em temas que discutam a deficiência visual que é responsável pelo maior percentual.

O Guia de Boas Práticas de Acessibilidade na Hotelaria desenvolvido em Lisboa pela Instituição Turismo de Portugal (GUIA DE BOAS PRÁTICAS..., 2012, p. 10) traz uma afirmação que merece ser ressaltada: "A acessibilidade de todas as pessoas a serviços e produtos apresenta fortes vantagens econômicas, em virtude da procura resultante de um número cada vez maior de consumidores com diferentes graus de limitação e deficiência". Essa afirmativa contém um argumento que destaca a relevância de colocar a acessibilidade em prática.

Cabe afirmar ainda que a atividade turística se constitui em um conjunto de serviços nos quais o atendimento não adequado em apenas um deles, pode prejudicar toda a experiência turística. Nesse aspecto, o tema acessibilidade é importante, principalmente no tocante à hospedagem, já que os hotéis fazem parte da composição do referido conjunto, além de compreenderem a hospitalidade e o ato de bem receber e de realizar um atendimento de qualidade a quem quer que seja. Por isso, faz-se necessária a pesquisa junto à classe hoteleira, com o objetivo de investigar como a mesma tem se preocupado com esse público.

\section{O turismo para pessoas com deficiência visual}

Entende-se que a questão da inclusão social das pessoas com deficiência é fator fundamental no desenvolvimento do país, uma vez que devem ser garantidos, além dos direitos constitucionais de ir e vir e o acesso à informação e à comunicação, níveis mais elevados de qualidade de vida por meio de atividades de lazer e turismo, todos esses são elementos dos direitos humanos e da cidadania (DUARTE, BORDA; MOURA; SPEZIA, 2015).

Assim, entende-se que o turismo pode e deve colaborar para que essa inclusão social ocorra, pois a atividade turística promove a interação entre todos os tipos de pessoas, com costumes e crenças dos mais variados. Além disso, como já foi citado anteriormente, o turismo está diretamente associado com a hospitalidade e com o ato de bem receber a todos. O próprio Código Mundial de Ética do Turismo organizado pela OMT em outubro de 1999 traz a informação de que a atividade turística deve ocorrer de forma harmônica, segura e respeitosa e informa em seu artigo 70 que as pessoas com deficiência, dentre outros grupos de pessoas, devem ter suas viagens facilitadas e encorajadas. Segundo Bezerra, Cruz e Coutinho (2012, p. 8):

Contudo se crê para que o turismo possa de fato contribuir para o desenvolvimento local e para a inclusão dos deficientes no turismo, é necessário que os processos resultantes da atividade turística tragam benefícios não apenas 
em termos econômicos, mas, também, que promovam a justiça social, a conservação cultural, além de permitir que os sujeitos sociais estejam incluídos nos processos de decisão e gestão das atividades a serem desenvolvidas.

A deficiência visual é parte do tema central do presente artigo e por este motivo necessita ser abordada com maior profundidade e detalhamento. Como já foi citado anteriormente, se enquadram na categoria de pessoas com deficiência visual, tanto as que possuem baixa visão, como aquelas com cegueira total, congênita ou adquirida. De acordo com Ribas (1985), a deficiência visual é considerada uma deficiência sensorial, assim como a auditiva. Para facilitar o estudo acerca da acessibilidade para pessoas com deficiência visual, faz-se necessário compreender melhor quais são as maiores dificuldades enfrentadas por elas e quais os recursos que já são utilizados para minimizar essas dificuldades.

Primeiramente, serão abordadas algumas das dificuldades que eles encontram no momento que precisam se deslocar de um lugar para outro com ou sem o auxílio de outra pessoa, bem como os diferentes recursos utilizados para a locomoção. Os perigos que a rua oferece para um deficiente visual são muitos, dentre eles podemos citar: buracos nas calçadas, semáforos sem sinalização sonora, diversos obstáculos pelo caminho e outros.

É importante ressaltar que, pelo fato de não possuírem a visão, o processo de aprendizagem e a percepção do mundo por pessoas com deficiência visual ocorre por meio dos outros sentidos (tato, audição, olfato, paladar), principalmente nos casos em que essa deficiência é congênita. De acordo com Santin e Simmons (1977, p. 5):

A experiência que uma criança cega tem de um grande edifício, por exemplo, é basicamente uma experiência de textura (áspera, estriada), de maleabilidade (dura), de som (tráfego, pessoas caminhando e conversando), e de olfato (argamassa, madeira). Para um vidente, a experiência do mesmo edifício é basicamente visual, focalizada simultaneamente no tamanho, no formato e na cor.

Por meio da informação supracitada, é possível compreender que a percepção das pessoas com deficiência visual é diferente. A audição, por exemplo, é muito utilizada para facilitar a locomoção, portanto, recursos auditivos para sinalizar ou trazer alguma informação, são de grande utilidade, como por exemplo, sinalização sonora em semáforos e elevadores.

A bengala e o cão guia também são alguns dos recursos utilizados para ter mais autonomia, entretanto, em alguns casos faz-se imprescindível a companhia de uma pessoa para guia-los 
durante todo o percurso, ou no caso de estarem sozinhos precisam contar com o apoio de desconhecidos para orientá-los ao longo do trajeto que estão percorrendo, para ajudar na hora de chamar um ônibus ou um taxi e até mesmo para evitar acidentes.

As bengalas constituem o principal recurso utilizado por pessoas com deficiência visual e permitem uma maior mobilidade, principalmente quando o lugar possui um piso tátil corretamente instalado e sem obstáculos no caminho.

A ABNT (NBR 9050, 2004) define: "piso tátil: Piso caracterizado pela diferenciação de textura em relação ao piso adjacente, destinado a constituir alerta ou linha guia, perceptível por pessoas com deficiência visual". Ainda de acordo com a referida norma, o piso tátil pode ser direcional ou alerta, dependendo da função que ele exerce. Podem ser observados nas figuras 1 e 2 os pisos táteis, direcional e alerta respectivamente.

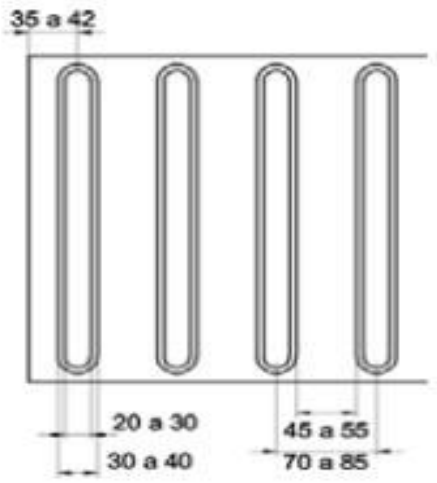

Figura 1 - Piso tátil direcional. Fonte: NBR 9050 (2004)

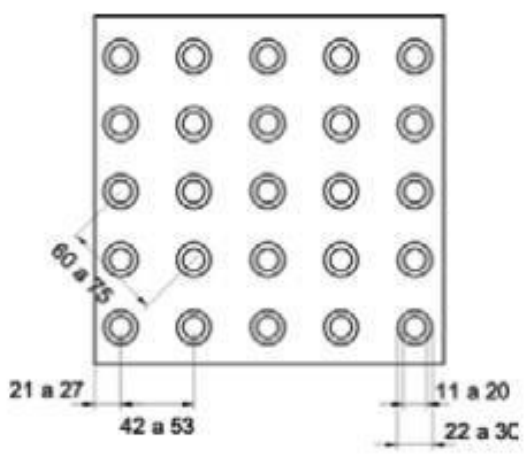

Figura 2 - Piso tátil alerta.

Após avaliar a questão da locomoção, é pertinente entender melhor sobre o processo de busca por educação, conhecimento, acesso a informação e autonomia enfrentado por essas pessoas ao longo dos anos. Segundo Baptista (2000), para que as pessoas com deficiência visual pudessem estudar um rapaz chamado Valentin Haüy (1745-1822) fundou em Paris no ano de 1784, a primeira escola para cegos e lá desenvolveu o método de confeccionar letras grandes, em alto relevo e móveis para que eles pudessem sentir as letras com as mãos e ler ou escrever com elas. Posteriormente um dos alunos da escola, chamado Luís Braille, que perdeu a visão quando ainda era pequeno desenvolveu o Sistema Braille, que foi adaptado a todas as línguas e é utilizado até hoje na educação de pessoas com deficiência visual. 
Ainda de acordo com Baptista (2000), desde o ano de 1854 o Sistema Braille foi difundido fora da França, chegando, dentre outros Países, ao Brasil. O acesso à educação foi durante muito tempo uma grande dificuldade para essas pessoas e apesar da facilidade que o braile trouxe, as instituições de ensino voltadas a esse público ainda são poucas e o acesso à informação por meio de livros, cardápios e outros informativos em braile, ainda são difíceis de encontrar.

É possível perceber que a luta das pessoas com deficiência visual para quebrar barreiras e levar uma vida digna é bastante antiga e que essas pessoas enfrentam muitas dificuldades em decorrência da falta de acessibilidade nos lugares. Além disso, por vezes eles ainda se deparam com o preconceito e com a falta de qualificação profissional notável em muitos funcionários. Então, a promoção da acessibilidade e a criação de normas e leis que os amparem tornam-se fundamentais no processo de eliminação de barreiras.

De acordo com o que já foi abordado anteriormente, cada tipo de deficiência possui características que Ihes são próprias e, por este motivo, necessitam de diferentes tipos de adaptabilidade para facilitar sua locomoção e interação com o meio. Em decorrência desse fato, é relevante acercarse de algumas questões relacionadas ao turismo para pessoas com deficiência visual.

Dados do Censo do IBGE revelaram que em 2000 a deficiência visual já era a que mais afetava a população brasileira, sendo 148 mil pessoas cegas e 2,4 milhões com grande dificuldade de enxergar. Posteriormente, o Censo de 2010 mostrou que até aquele ano a deficiência visual ainda era a que mais afetava homens e mulheres acometendo 35,8 milhões de brasileiros. Ao pesquisar a taxa de atividade, que mede o percentual das pessoas economicamente ativas na população de 10 anos ou mais de idade, foi possível verificar que as pessoas com deficiência visual são as que mais estão inseridas do mercado de trabalho se comparado às outras deficiências.

A partir dessas reflexões, o turismo acessível encontra-se no âmbito do turismo responsável visto que as pessoas que possuem algum tipo de deficiência necessitam da promoção da acessibilidade para praticarem a atividade turística.

Nesta conjuntura, é imprescindível criar condições adequadas de estímulo e acessibilidade, respeitando a todos e objetivando a inclusão das pessoas com deficiência, não só na atividade turística, mas em todo âmbito social (BIZINELLI, MANOSSO, GIMENES-MINASSE; SOUZA, 2014). Ao analisar o termo acessibilidade, pode-se afirmar que a mesma consiste em permitir o acesso das pessoas aos espaços, eliminando as barreiras que impedem ou dificultam esse acesso. A Lei no 10.098 traz a seguinte definição de barreiras: "qualquer entrave ou obstáculo que limite ou 
impeça o acesso, a liberdade de movimento e a circulação com segurança das pessoas" (BRASIL, 2000).

O Relatório Mundial sobre a Deficiência (2011, p. 309) possui uma conceituação mais genérica, relacionando a acessibilidade ao grau de possibilidade de acesso: "Acessibilidade descreve o grau em que um ambiente, serviço ou produto permite o acesso do maior número possível de pessoas, especialmente pessoas com deficiência".

Desta forma, o MTur em parceria com a AVAPE executou no município de Socorro em São Paulo um projeto de Sensibilização para o Turismo Acessível que ocasionou em 2009 na criação de quatro cartilhas importantes.

A cartilha de volume III chamada "Bem atender do Turismo Acessível" apresenta informações relevantes a respeito da qualificação no atendimento dos prestadores de serviços em relação a turistas com deficiência visual. Tal cartilha apresenta as seguintes recomendações:

- Quando estiver ao lado da pessoa com deficiência visual ou cega, se apresente, faça com que ela perceba a sua presença e se identifique sempre;

- Ao apresentar alguém cego faça com que a pessoa apresentada fique de frente à pessoa cega, de modo que ela estenda a mão para o lado certo;

- Caso note que a pessoa cega ou com deficiência visual esteja necessitando de ajuda, primeiro identifique-se, e pergunte se ela aceita seu auxílio. Caso a resposta seja positiva, pergunte qual é a melhor forma de ajudá-la para não ocorrer constrangimentos de ambas as partes;

- Seja claro e objetivo ao explicar direções à pessoa cega ou com deficiência visual;

- Ao conduzir um pessoa cega:

- dê-lhe o braço para que a mesma possa acompanhar seu movimento;

- não a deixe falando sozinha;

- Em lugares estreitos, sempre caminhe na frente da pessoa com deficiência e coloque seu braço para trás, para ela ir seguindo você;

- Ao conduzir um cego a uma cadeira guie a mão para o encosto, informando se a cadeira tem braços ou não;

- Quando conduzir a pessoa cega ou com deficiência visual, avise os possíveis obstáculos que estão à sua frente como buracos, degraus, possíveis desníveis, tipos de pisos; 
- Comunique-se com seu tom de voz normal, não precisa gritar com a pessoa cega ou com deficiência visual, a menos que ela solicite, devido algum problema auditivo;

- Com pessoas que possuem baixa visão (sérias dificuldades visuais) proceda com o mesmo respeito, perguntando-Ihe se precisa de ajuda se notar que ela está com dificuldades;

- Informe à pessoa cega quando estiver passando por um obstáculo qualquer evitando assim possíveis acidentes;

- Nunca distraia um cão guia, pois ele tem a responsabilidade de guiar seu dono que tem uma deficiência visual (BEM ATENDER DO TURISMO ACESSíVEL, 2009).

A partir das recomendações citadas, tornam-se claras as diferenças que devem existir no atendimento oferecido à uma pessoa com deficiência visual. Além disso a referida cartilha apresenta também algumas informações acerca do sistema braile, que já foi abordado anteriormente.

\section{Procedimentos Metodológicos}

Quanto aos objetivos, a pesquisa realizada foi exploratória, pois traz informações que facilitam a compreensão acerca da acessibilidade nos setores hoteleiros sul e norte de Brasília e, para tal, se utiliza de um levantamento bibliográfico e uma pesquisa documental combinados com a aplicação de dois instrumentos de coleta de dados, sendo eles um roteiro de entrevista e um roteiro de observação.

No tocante à pesquisa bibliográfica, foram utilizados diversos livros e artigos que abordam assuntos relevantes acerca do tema do presente artigo. Já no que se refere à pesquisa documental, foram utilizados normas, decretos e leis com o objetivo de auxiliar na compreensão da relevância do assunto.

Quanto à pesquisa de campo, um roteiro de entrevista foi aplicado aos funcionários dos hotéis com o objetivo de analisar a forma de atendimento e os recursos oferecidos pelos estabelecimentos. 0 referido instrumento continha o total de 6 perguntas, que visavam verificar a qualificação profissional para o atendimento de pessoas com deficiência visual, bem como a ocorrência ou não de algum tipo de fiscalização que averiguasse a acessibilidade nos estabelecimentos.

Como mencionado anteriormente, além da aplicação do roteiro de entrevista, foi utilizado um roteiro de observação. O mesmo se deu por meio da adaptação do instrumento de pesquisa elaborado pelo Conselho Regional de Engenharia, Arquitetura e Agronomia do Rio de Janeiro 
(CREA-RJ, 2015), sendo o próprio utilizado como base para a observação das condições atuais dos estabelecimentos no que se refere a acessibilidade para pessoas com deficiência visual.

Os dois instrumentos de coleta de dados foram aplicados em hotéis dos setores hoteleiros sul e norte de Brasília no ano de 2015, perfazendo o total de 30 hotéis.

Para a seleção dos hotéis, primeiramente foi realizada uma listagem de todos os estabelecimentos dos setores hoteleiros sul e norte de Brasília com base nas informações divulgadas pela Secretaria de Turismo no site do Observatório do Turismo do Distrito Federal (2015). De posse dos referidos dados, realizou-se um primeiro contato por telefone com todos os empreendimentos informando sobre a pesquisa e solicitando a permissão para aplicar os dois instrumentos de coleta de dados. Dos 30 estabelecimentos pesquisados, 16 foram investigados juntamente com o Presidente da Associação de Amigos dos Deficientes Visuais de Brasília.

Ressalta-se que o auxílio de uma pessoa com deficiência visual ao longo da pesquisa de campo foi fundamental, pois, além de oferecer um conhecimento mais amplo acerca das necessidades e barreiras enfrentadas por essas pessoas, era alguém que tinha o hábito de viajar e pôde verificar a real funcionalidade das adaptações encontradas e assegurar se elas estavam atendendo, de fato, as necessidades das pessoas com deficiência visual.

\section{Resultado do roteiro de entrevista}

A coleta de dados se inicia com questionamentos acerca da qualificação profissional no que se refere ao atendimento às pessoas com deficiência visual e se o estabelecimento recebe ou não algum órgão fiscalizador. Seguem no Quadro 1 as respostas fornecidas pelas 30 pessoas entrevistadas nos setores hoteleiros sul e norte:

\begin{tabular}{|l|l|l|c|}
\hline \multicolumn{1}{|c|}{ Perguntas } & Sim & Não & Não se aplica \\
\hline $\begin{array}{l}\text { 1. Você se considera apto (a) para lidar com pessoas com } \\
\text { deficiência visual? }\end{array}$ & 23 & 7 & 0 \\
\hline $\begin{array}{l}\text { 2. O hotel oferece algum treinamento para preparar os } \\
\text { funcionários para receber pessoas com deficiência visual? }\end{array}$ & 8 & 22 & 0 \\
\hline $\begin{array}{l}\text { 3. Você acha importante que seja oferecido algum } \\
\text { treinamento? Justifique sua resposta. }\end{array}$ & 29 & 1 & 0 \\
\hline $\begin{array}{l}\text { 4. O restaurante do hotel possui cardápio em braile? Caso } \\
\text { não possua, justifique o motivo. }\end{array}$ & 8 & 20 & 2 \\
\hline $\begin{array}{l}\text { 5. O empreendimento recebe a visita de algum órgão } \\
\text { fiscalizador para verificar a acessibilidade do local? Caso } \\
\text { receba, informe o nome do órgão. }\end{array}$ & & & \\
\hline
\end{tabular}

Quadro 1. Treinamento para atender pessoas com deficiência visual 
É relevante ressaltar que 23 dos 30 entrevistados se consideram aptos a atender pessoas com deficiência visual, entretanto, a maioria dos empreendimentos (22 dos 30 analisados) não oferece nenhum treinamento para preparar essas pessoas para realizar esse atendimento. Nota-se também que 29 dos entrevistados acham esse tipo de treinamento importante e dos 26 que justificaram sua resposta, 13 informaram que o treinamento era importante para atender melhor aos hóspedes e saber auxilia-los em suas necessidades. A partir dessas informações, é possível verificar que apesar de um número relevante de funcionários se considerar apto a receber pessoas com deficiência visual, percebe-se que não há treinamento para oferecer um serviço de maior qualidade. Uma pesquisa realizada por Faria e Mota (2012) ressalta a necessidade de treinamento, pois o fator "atendimento" foi bastante apontado como restrição ao lazer de pessoas com deficiência visual.

Quanto ao cardápio em braile, com exceção de 2 hotéis (um que não possuía restaurante e outro que não tinha nenhum cardápio no restaurante), os números apontam que a maioria dos hotéis visitados (20 estabelecimentos) ainda não possui o cardápio para pessoas com deficiência visual, todos os entrevistados justificaram a resposta: 7 pessoas não sabiam o motivo de não possuir cardápio em braile e 4 informaram que a demanda não era significativa. Entretanto, cabe destacar a resposta de 1 dos entrevistados que justificou da seguinte forma: "achamos que a pessoa que acompanha o deficiente, auxilia nessa função". Percebe-se que em muitos empreendimentos as pessoas não souberam informar o motivo de não oferecer o referido cardápio, ou afirmaram que a demanda não era suficiente para justificar a oferta, contudo, é interessante sobressair que um dos entrevistados, ao afirmar que era papel do acompanhante auxiliar a pessoa com deficiência visual, não levou em conta a autonomia desses clientes. Cabe afirmar que alguns lugares do Brasil já possuem uma lei estadual que obriga determinados estabelecimentos a oferecer cardápio em braile. O Rio de Janeiro, por exemplo, possui a Lei 3879 (2002) que traz em seu artigo 10 a seguinte redação: "Ficam obrigados os bares, restaurantes, lanchonetes, hotéis e motéis a colocarem à disposição dos fregueses deficientes visuais, cardápios em braile". Fica clara a obrigatoriedade do cardápio nos hotéis do Rio de Janeiro. Em Brasília, o Projeto de Lei 1694 (1999) trata apenas da obrigatoriedade em bares e restaurantes.

Os 8 cardápios em braile encontrados ao longo da pesquisa foram avaliados pelo Presidente da Associação de Amigos dos Deficientes Visuais de Brasília que estava acompanhando as autoras. Suas impressões foram: "Os cardápios estavam corretos e possuíam as informações necessárias, entretanto, contatou-se que 2 empreendimentos estavam com os valores desatualizados". Esses empreendimentos informaram que haviam mudado os preços recentemente e em breve iriam atualizar os cardápios em braile. 
A questão de número 6 permite verificar que 16 hotéis informaram que recebiam a visita de um órgão fiscalizador, e 14 informaram que não recebiam. Dentre os que recebem essa visita, 9 informaram que o órgão responsável era a AGEFIS e 1 afirmou que era a EMBRATUR (só que este não possui esta função, apesar de apontada pelos entrevistados como tal) já os outros 6 não sabiam informar o nome do órgão. Diante dessas afirmações, cabe enfatizar a necessidade da fiscalização, que colabora para que as normas sejam cumpridas. Vaz $(2002$, p. 24) traz a seguinte afirmação: "Outra grande barreira ao cumprimento da legislação é a falta de fiscalização, quer à adaptação das pré-existências quer ao cumprimento desta por parte dos novos projetos". Então, compreende-se que a falta de fiscalização pode ser uma barreira para o cumprimento da legislação e consequentemente para a implementação da acessibilidade.

Quando questionados sobre a frequência com que o estabelecimento recebia pessoas com deficiência visual, 27 dos entrevistados afirmam que é um público pouco frequente ou que não recebem essas pessoas. Cabe aqui uma reflexão, pois, como foi assinalado por Faria e Motta (2012), a falta de acessibilidade, a falta de qualificação profissional para atender pessoas com deficiência e/ou a falta de informações sobre os recursos oferecidos pelo hotel para atender as necessidades dessas pessoas, constituem barreiras para o lazer e podem, em alguns casos, fazer com que elas optem por não realizar uma viagem.

Com relação às respostas obtidas na Questão 1, o Presidente da Associação de Amigos dos Deficientes Visuais de Brasília Lafaiete fez a seguinte afirmação: "as pessoas justificam a falta de acessibilidade com baixa demanda, mas na realidade o processo é inverso, a baixa demanda ocorre justamente pela falta de acessibilidade, pois se o hotel não se preocupa em oferecer o mínimo de acessibilidade para que a gente possa se hospedar com segurança e autonomia, nós só iremos nos hospedar lá se não houver outra opção".

Então, é importante analisar que a baixa frequência de pessoas com deficiência visual nos empreendimentos pode estar ocorrendo devido ao fato dos mesmos não estarem preparados para atender esses turistas.

Por meio das respostas obtidas no roteiro de entrevistas, é possível perceber a relevância do treinamento para que os funcionários passem a compreender melhor as necessidades dos clientes que possuem algum tipo de deficiência, pois esse segmento possui necessidades específicas e, portanto, demandam um atendimento diferenciado.

Através do treinamento, os funcionários se tornam aptos a realizar um atendimento mais hospitaleiro, fazendo com que os hospedes se sintam acolhidos e impelidos a retornar ao empreendimento. Além disso, passam a colaborar com o processo de inclusão social dessas 
pessoas, por meios da eliminação de barreiras atitudinais. De acordo com Maciel (2000, p. 54), "deve-se lembrar, sempre, que o princípio fundamental da sociedade inclusiva é o de que todas as pessoas portadoras de deficiência devem ter suas necessidades especiais atendidas. É no atendimento das diversidades que se encontra a democracia".

\section{Resultado do roteiro de observação}

No segundo momento da coleta de dados aplicou-se um roteiro de observação com o objetivo de investigar in loco como era, de fato, a acessibilidade do estabelecimento para esse público. 0 roteiro de observação permitiu obter informações relevantes acerca das condições gerais de acessibilidade nas instalações dos hotéis pesquisados. O referido instrumento foi dividido em quatro blocos, são eles: circulação do hall, circulação dos quartos, circulação geral e circulação vertical (elevadores).

Em relação a circulação do hall, o Quadro 2 apresenta as respostas referentes a acessibilidade desde a rua até o balcão de atendimento, bem como as instalações da recepção:

\begin{tabular}{|l|l|l|l|}
\hline \multicolumn{1}{|c|}{ Respostas } & Sim & Não & Não se aplica \\
\hline $\begin{array}{l}\text { 1. O percurso que une a edificação á via pública, às } \\
\text { edificações e aos serviços anexos de uso comum e aos } \\
\text { edifícios vizinhos é acessível? }\end{array}$ & 3 & 27 & 0 \\
\hline $\begin{array}{l}\text { 2. Pelo menos um dos acessos ao interior da edificação está } \\
\text { livre de barreiras arquitetônicas e de obstáculos que } \\
\text { impeçam ou dificultem a acessibilidade? }\end{array}$ & 25 & 5 & 0 \\
\hline $\begin{array}{l}\text { 3. A circulação é acessível desde a rua até o saguão onde } \\
\text { se localiza o elevador? }\end{array}$ & & & \\
\hline $\begin{array}{l}\text { 4. Se não há elevador ou outro equipamento } \\
\text { eletromecânico acessível, há rampas ligando os } \\
\text { pavimentos? }\end{array}$ & 4 & 4 & 22 \\
\hline $\begin{array}{l}\text { 5. Há rampa em qualquer caso onde ocorra um desnível } \\
\text { ma }\end{array}$ & & 4 & 24 \\
$\begin{array}{l}\text { ior que 1,5cm e menor que 48 cm, já que são proibidos } \\
\text { lance de escadas com menos de três degraus? }\end{array}$ & 2 & & \\
\hline $\begin{array}{l}\text { 6. Na entrada dos prédios totalmente adaptados às } \\
\text { exigências desta lei, está fixado o símbolo internacional de } \\
\text { acessibilidade? }\end{array}$ & 0 & 0 & 30 \\
\hline
\end{tabular}

Quadro 2. Circulação do Hall.

No tocante a circulação do hall, verificou-se que 27 hotéis não possuem acessibilidade no percurso que une o empreendimento à via pública e aos outros empreendimentos vizinhos e também não possuem circulação acessível desde a rua até o saguão onde se localiza o elevador. Cabe destacar 
que os setores hoteleiros sul e norte de Brasília enfrentam um grande problema de mobilidade urbana, pois as calçadas quebradas ou a ausência delas em conjunto com o grande fluxo de carros dificulta a circulação de pedestres, principalmente daqueles que possuem alguma limitação. Entretanto, a maioria dos hotéis (25) possui ao menos um acesso ao seu interior, livre de barreiras arquitetônicas e obstáculos. Na maioria dos hotéis (22 empreendimentos) há elevador e entre os 8 que não os possuem, 4 tem rampas ligando os pavimentos e 4 não. As observações apontam que nenhum dos empreendimentos visitados é totalmente adaptado.

Por meio da observação, é possível afirmar também que, devido ao fato de não haver acessibilidade no percurso fora das edificações, um deficiente visual que for se hospedar em qualquer um dos hotéis presentes nos setores hoteleiros sul e norte precisa, necessariamente, de um veículo (taxi, por exemplo) que o deixe e busque na entrada do hotel.

Com relação à circulação do hall nos hotéis acessíveis, o Presidente da Associação de Amigos dos Deficientes Visuais de Brasília fez o seguinte comentário: “a quantidade de hotéis que possuem um acesso seguro é tão pequena que quando nos deparamos com um lugar assim precisamos tirar uma foto para mostrar aos outros como deve ser". A seguir, tem-se a Figura 2 de um dos hotéis que possuía piso tátil.

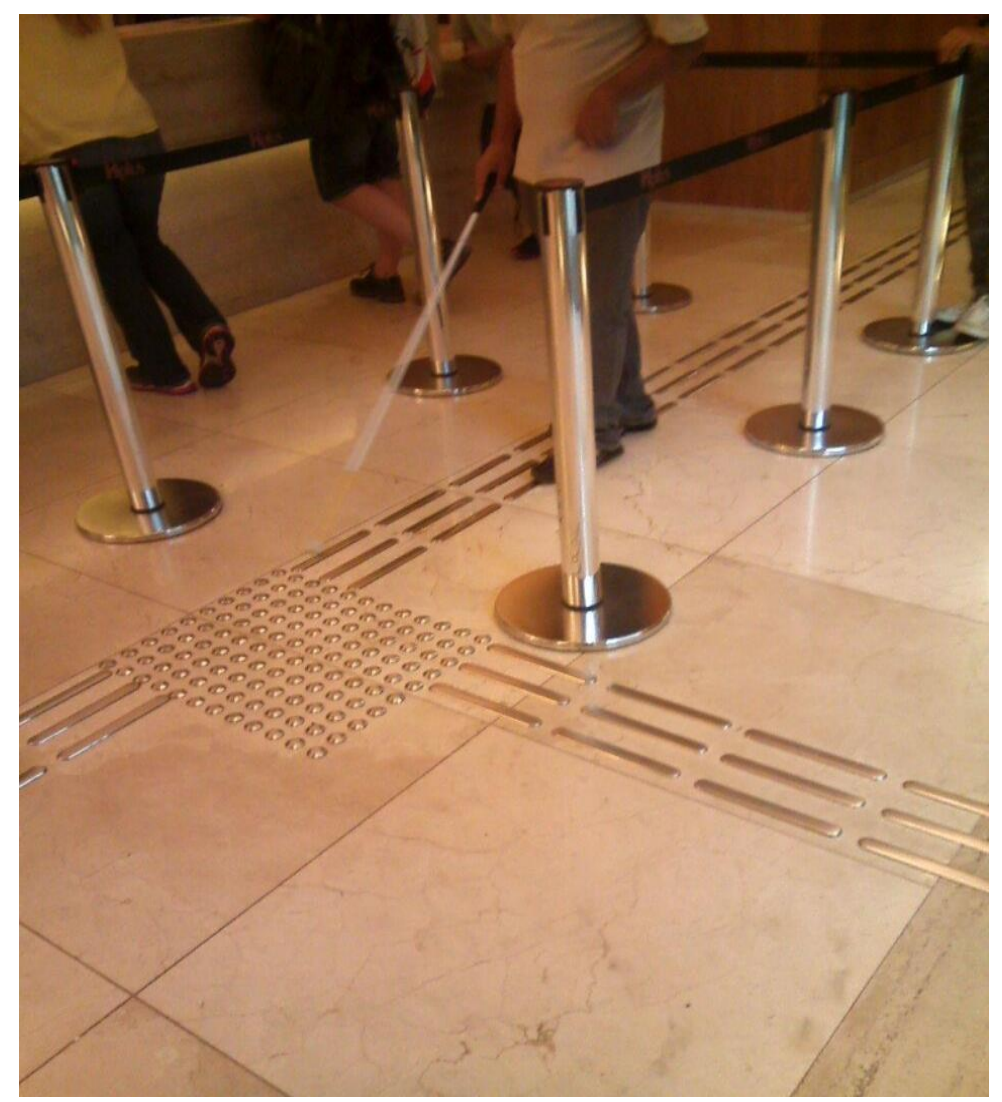

Figura 3. Piso Tátil 
O segundo bloco de questões refere-se como está a acessibilidade para pessoas com deficiência visual nos quartos adaptados. O Quadro 3 apresenta os resultados.

\begin{tabular}{|l|l|l|l|}
\hline \multicolumn{1}{|c|}{ Respostas: } & Sim & Não & $\begin{array}{l}\text { Não se } \\
\text { aplica }\end{array}$ \\
\hline $\begin{array}{l}\text { 1. O piso é revestido com material antiderrapante, plano, } \\
\text { com desnível máximo de 0,5cm? }\end{array}$ & 28 & 1 & 1 \\
\hline $\begin{array}{l}\text { 2.A sinalização visual tem dimensão apropriada para pessoas } \\
\text { com baixa visão? }\end{array}$ & 0 & 29 & 1 \\
\hline 3.A sinalização visual é em cores contrastantes? & 0 & 29 & 1 \\
\hline $\begin{array}{l}\text { 4. A porta do banheiro ou boxe para o vaso sanitário está } \\
\text { disposta de maneira a permitir sua completa abertura? }\end{array}$ & 12 & 0 & 18 \\
\hline $\begin{array}{l}\text { 5. A maçaneta ou trinco da porta do sanitário é do tipo } \\
\text { alavanca? }\end{array}$ & 4 & 6 & 20 \\
\hline 6. Há braile ao lado dos comandos no quarto e no banheiro? & 0 & 29 & 1 \\
\hline
\end{tabular}

Quadro 3. Circulação dos Quartos

No tocante a circulação dos quartos, 29 hotéis possuíam ao menos um quarto adaptado, apenas um não tinha o piso revestido com material plano com desnível máximo de 0,5 . No que se refere a porta do banheiro, em 12 quartos a porta abria por completo, enquanto nos outros, não havia porta; já em relação as maçanetas, a maior frequência de respostas foi "não se aplica", devido ao fato de alguns não possuírem porta e outros possuírem porta de correr. Nenhum dos quartos possui sinalização visual apropriada para pessoas com baixa visão, nem braile ao lado dos comandos no quarto e no banheiro.

O que foi possível verificar nos quartos é que as adaptações que eles possuíam estavam voltadas apenas as necessidades de pessoas com limitação motora, não possuindo nenhuma adaptação para os outros tipos de deficiência.

O terceiro bloco, no qual as respostas se encontram no Quadro 4, foi formado por perguntas referentes a circulação geral e visa analisar as condições de acessibilidade em todas as áreas de uso comum do hotel.

\begin{tabular}{|l|l|l|l|}
\hline \multicolumn{1}{|c|}{ Respostas: } & Sim & Não & $\begin{array}{l}\text { Aão se } \\
\text { Aplica }\end{array}$ \\
\hline $\begin{array}{l}\text { 1. O piso dos corredores e passagens é revestido com material } \\
\text { antiderrapante, plano, com desnível máximo de 0,5cm? }\end{array}$ & 28 & 2 & 0 \\
\hline 2. Há piso tátil direcional? & 2 & 28 & 0 \\
\hline
\end{tabular}




\begin{tabular}{|l|l|l|l|}
\hline $\begin{array}{l}\text { 3. Há piso tátil de alerta próximo às escadas, elevadores e sob o } \\
\text { mobiliário suspenso? }\end{array}$ & 3 & 27 & 0 \\
\hline $\begin{array}{l}\text { 4. A sinalização visual tem dimensão apropriada para pessoas } \\
\text { com baixa visão? }\end{array}$ & 1 & 29 & 0 \\
\hline $\begin{array}{l}\text { 5. Em degraus isolados, há sinalização tátil de alerta localizada } \\
\text { antes do início e após o término da mudança de planos nos } \\
\text { desníveis? }\end{array}$ & 3 & 27 & 0 \\
\hline $\begin{array}{l}\text { 6. Obstáculos como caixas de coleta, lixeira, floreiras, extintores } \\
\text { de incêndio e outros estão fora da zona de circulação? }\end{array}$ & 3 & 27 & 0 \\
\hline 7. A sinalização visual é em cores contrastantes? & 0 & 30 & 0 \\
\hline
\end{tabular}

Quadro 4. Circulação Geral

No Quadro 4 é possível verificar que 28 dos 30 hotéis visitados possuíam um piso plano e com desnível máximo de $0.5 \mathrm{~cm}$ em todas as suas dependências. Lamentavelmente, quase todos os hotéis (28 empreendimentos) não possuíam o piso tátil direcional, conforme preconizado pela norma da ABNT (NBR 9050, 2004). Tal piso tem o objetivo de servir de guia para a pessoa com deficiência visual. Da mesma forma, o piso de alerta não estava presente em 27 dos 30 hotéis pesquisados.

As informações do Quadro permitem verificar também que a sinalização visual não possui dimensão apropriada e nem cores contrastantes para facilitar a visualização por pessoas com deficiência visual que possuem baixa visão. Além disso, em 27 hotéis foram encontrados obstáculos obstruindo a zona de circulação. Com esses dados, considera-se que, no tocante a circulação geral, os hotéis não estão aptos a receber pessoas com deficiência visual, pois, devido à falta de acessibilidade na circulação geral, essas pessoas não conseguem circular com autonomia e segurança pelas dependências do hotel.

O quarto e último bloco, demonstrado por meio do Quadro 5, apresenta informações referentes à circulação vertical e analisa a acessibilidade nos elevadores.

\begin{tabular}{|l|l|l|c|}
\hline \multicolumn{1}{|c|}{ Respostas: } & Sim & Não & Não se aplica \\
\hline $\begin{array}{l}\text { 1. O tempo de permanência da porta aberta está entre 5s e 15s? } \\
22\end{array}$ & 0 & 8 \\
\hline $\begin{array}{l}\text { 2. O piso da cabine tem cor contrastante com a do piso do } \\
\text { pavimento? }\end{array}$ & 14 & 8 & 8 \\
\hline $\begin{array}{l}\text { 3. Os botões de chamada externos têm dimensão mínima de } \\
\text { 19mm, excluindo-se a aba? }\end{array}$ & 20 & 2 & 8 \\
\hline $\begin{array}{l}\text { 4. Os botões de chamada externos e do painel de comando são } \\
\text { providos de indicação visual e tátil? }\end{array}$ & 18 & 4 & 8 \\
\hline $\begin{array}{l}\text { 5. Os comandos de emergência estão agrupados na parte } \\
\text { inferior do painel de comandos da cabine? }\end{array}$ & 21 & 1 & 8 \\
\hline 6. Há sonorização? & 8 & 14 & 8 \\
\hline
\end{tabular}




\begin{tabular}{|l|l|l|l|}
\hline $\begin{array}{l}\text { 7. A dimensão mínima das letras e números das marcações dos } \\
\text { comandos é de } 1,6 \mathrm{~cm} \text { ? }\end{array}$ & 21 & 1 & 8 \\
\hline $\begin{array}{l}\text { 8. Os capachos embutidos no piso são nivelados com saliência } \\
\text { menor que } 0,5 \mathrm{~cm} \text { de altura? }\end{array}$ & 6 & 0 & 24 \\
\hline $\begin{array}{l}\text { 9. Elevadores que atendem as exigências da NBR 13,994/00 estão } \\
\text { identificados como o Símbolo Internacional de Acesso? }\end{array}$ & 0 & 6 & 24 \\
\hline
\end{tabular}

Quadro 5. Circulação Vertical - Elevadores

É relevante destacar que 8 dos 30 hotéis pesquisados não possuíam elevador e que os 22 elevadores avaliados possuíam o tempo de permanência da porta aberta entre 5 e 15 segundos, obedecendo ao critério estabelecido no item 5.1.6 da ABNT (NBR 13994, 2000). Grande parte dos elevadores (14 dentre os 22) possuíam o piso da cabine em cor contrastante, o que facilita a visualização por pessoas com baixa visão. A dimensão dos botões de chamada externos também estava correta na maioria dos elevadores (20 dentre os 22), bem como a indicação visual e tátil encontrada em 18 elevadores e os comandos de emergência agrupados na parte inferior do painel, encontrado em 21 elevadores.

A sonorização, que informa o andar em que o elevador se encontra e se ele está subindo ou descendo é fundamental para que a pessoa com deficiência visual se localize. Lamentavelmente, 14 dos 22 elevadores não possuíam essa sinalização. As letras e números das marcações possuíam a dimensão adequada para facilitar a visualização por pessoas com baixa visão em 21 elevadores. Além disso, dos 22 elevadores observados, 16 não possuíam capachos embutidos e os outros 6 que possuíam estavam nivelados com saliência menor que $0,5 \mathrm{~cm}$ de altura. Ainda sobre aos elevadores, 16 não atendiam as normas da ABNT (NBR 13994, 2000) e os 6 que atendiam não possuíam o Símbolo Internacional de Acesso para identificá-los.

Os resultados mostram que os quesitos de acessibilidade encontrados nos elevadores pesquisados, em sua maioria atendem os requisitos da Norma, entretanto, a falta de sonorização dificulta bastante a localização por parte das pessoas com deficiência visual e se configura como barreira para a locomoção autônoma dessas pessoas. É interessante ressaltar que no ano de 2011 foi elaborado o Guia Novos Rumos pelo Ministério do Turismo (2011, p. 312) que verificou a acessibilidade em atrativos turísticos, estabelecimentos de alimentação e meios de hospedagem para pessoas com diferentes tipos de deficiência e trouxe a seguinte constatação no tocante aos hotéis: "Para pessoas com deficiência visual, há poucas informações em braile ou letras em 
relevo, adaptações presentes somente nos elevadores". Constata-se que os resultados obtidos pelo Guia são muito semelhantes aos resultados obtidos na presente pesquisa.

\section{Considerações finais}

O presente artigo teve como objetivo a análise da situação dos hotéis dos setores hoteleiros sul e norte de Brasília no tocante a acessibilidade para pessoas com deficiência visual.

Para tanto, foi realizada uma pesquisa bibliográfica e documental, que serviram de embasamento para melhor compreensão do tema e de sua relevância. Além disso, foram aplicados dois instrumentos de coleta de dados com a finalidade de verificar na prática as condições dos empreendimentos para receber pessoas com deficiência visual. Ao total, foram investigados 30 estabelecimentos.

A contextualização do referencial teórico permitiu avaliar que o tema "acessibilidade" é relevante, foi possível verificar também que as pessoas com deficiência estão pleiteando seus direitos e buscando conquistar seu espaço na sociedade por meio da inclusão social. A própria sociedade está cobrando dos empreendimentos uma postura mais responsável que atenda de forma plena as leis, decretos e normas existentes.

No que se refere à pesquisa de campo, um dos instrumentos de coleta de dados aplicado foi o roteiro de entrevista, que permitiu obter informações acerca dos entrevistados, sua qualificação profissional para receber pessoas com deficiência visual, a oferta de cardápio em braile nos restaurantes dos hotéis, a presença ou não de um órgão fiscalizador que realize visitas periódicas para avaliar as condições de acessibilidade do hotel e a frequência com que os empreendimentos recebem pessoas com deficiência visual. Por meio do referido instrumento, foi possível concluir que a maioria dos entrevistados não recebia nenhum treinamento para atender pessoas com deficiência visual, mas, apesar de informar que esse público não era muito frequente, estavam interessadas em aprender a acolher melhor esses clientes, ressaltando a importância do treinamento para suprir as necessidades desse segmento. Além disso, constatou-se que nem todos os empreendimentos recebem a visita de um órgão fiscalizador, o que leva a reflexão de que a falta de fiscalização acaba, em alguns casos, acarretando no descumprimento das normas existentes.

O outro instrumento utilizado na coleta de dados foi o roteiro de observação. O mesmo permitiu verificar as condições de acessibilidade na circulação da rua até o saguão do hotel, dos quartos adaptados, da circulação geral nas dependências de uso comum e dos elevadores. Esse instrumento 
permitiu constatar que, de uma forma geral, os hotéis dos setores hoteleiros sul e norte de Brasília não oferecem recursos para receber esses hóspedes. De todos os locais investigados, os elevadores foram aqueles que mais atenderam as normas de acessibilidade para o deficiente visual contemplando alguns itens voltados a acessibilidade.

Com base no levantamento realizado em Brasília sugere-se que sejam realizados estudos em outras cidades brasileiras, a fim de verificar se a realidade diagnosticada na Capital Federal se repete em outros cenários. Além disso, sugere-se que sejam realizados programas/projetos voltados para uma maior sensibilização do setor hoteleiro quanto a importância do pleno atendimento a esse público, pois a pesquisa apontou que, quando se aborda o tema acessibilidade, o enfoque está mais voltado para a limitação motora e não visual. Da mesma forma, sugere-se uma atuação mais firme de órgãos fiscalizadores com punições para aqueles estabelecimentos que não possuam os requisitos necessários para atender de forma plena essas pessoas.

\section{Referências}

ABNT NBR 9050. Associação Brasileira de Normas Técnicas. Acessibilidade a edificações, mobiliário, espaços e equipamentos urbanos. Rio de Janeiro, 2004. Disponível em: <http://www.pessoacomdeficiencia.gov.br/app/sites/default/files/arquivos/\%5Bfield_generico _imagens-filefield-description\%5D_24.pdf> Acesso em: 05 mai. 2015.

ABNT NBR 13994. Associação Brasileira de Normas Técnicas. Elevadores de passageiros elevadores para transporte de pessoa portadora de deficiência. Rio de Janeiro, 2002. Disponível em: < http://www.mpf.mp.br/atuacao-tematica/pfdc/institucional/grupos-de-trabalho/inclusaopessoas-deficiencia/atuacao/legislacao/docs/ABNT-NBR-13994.pdf/view> Acesso em 10 jun. 2015.

BAPTISTA, J. A. L. S. A invenção do Braille e a sua Importância na Vida dos Cegos. Lisboa: Secretariado Nacional para a Reabilitação e Integração das Pessoas com Deficiência. Comissão de Braille, 2000.

BEZERRA, Maria Adriana Sena; CRUZ, Luzia Nara; COUTINHO, Helen Rita Menezes. Inclusão social das pessoas com deficiência visual nos atrativos turísticos da cidade de Manaus: Centro Cultural dos Povos da Amazônia, Palacete Provincial e Teatro Amazonas. Anais... IX Seminário da Associação Nacional de Pesquisa e Pós-Graduação em Turismo - Anptur. São Paulo, 2012.

BIZINELLI, C.; MANOSSO, F.; GIMENES-MINASSE, M. H. S.; SOUZA, S. do R. de. Turismo \& Sociedade. Curitiba, v. 7, n. 3, p. 495-522, julho de 2014. Dossiê sobre Enoturismo.

BRASIL, Decreto № 5.296, de 2 de dezembro de 2004. Regulamenta as Leis nos 10.048, de 8 de novembro de 2000, que dá prioridade de atendimento às pessoas que especifica, e 10.098, de 19 de dezembro de 2000, que estabelece normas gerais e critérios básicos para a promoção da acessibilidade das pessoas portadoras de deficiência ou com mobilidade reduzida, e dá outras providências. Diário Oficial [da] União, Poder Legislativo, Brasília, DF. Disponível em: 
<http://www2.camara.leg.br/legin/fed/decret/2004/decreto-5296-2-

dezembro-2004-534980normaatualizada-pe.html> Acesso em: 20 jun. 2015.

BRASIL, Decreto № 5.904, de 21 de dezembro de 2006. Regulamenta a Lei no 11.126, de 27 de junho de 2005, que dispõe sobre o direito da pessoa com deficiência visual de ingressar e permanecer em ambientes de uso coletivo acompanhada de cão-guia e dá outras providências. Diário Oficial [da] União, Poder Legislativo, Brasília, DF. Disponível em:

<http://www2.camara.leg.br/legin/fed/decret/2006/decreto-5904-21-setembro-2006-545552publicacaooriginal-58687-pe.html> Acesso em: 17 jun. 2015.

BRASIL, Lei 7.405, de 12 de novembro de 1985. Torna obrigatória a colocação do "Símbolo Internacional de Acesso" em todos os locais e serviços que permitam sua utilização por pessoas portadoras de deficiência e dá outras providências. Diário Oficial [da] União, Poder Legislativo, Brasília, DF. Disponível em: <http://www2.camara.leg.br/legin/fed/lei/19801987/lei-7405-12-novembro-1985-367964-publicacaooriginal-1-pl.html> Acesso em: 17 jun. 2015.

BRASIL, Projeto de Lei 1694. Dispõe sobre a obrigatoriedade de cardápio em Método Braille nos restaurantes, bares e lanchonetes. Disponível em: < http://www.camara.gov.br/proposicoesWeb/fichadetramitacao?idProposicao=17093> Acesso em 20 maio 2015.

BRASIL, Lei № 3879, de 25 de junho de 2002. Obriga os bares, restaurantes, lanchonetes, hotéis e motéis a colocarem à disposição dos fregueses deficientes visuais, cardápio em braile. Diário Oficial do Rio de Janeiro, Rio de Janeiro. Disponível em: < http://www.jusbrasil.com.br/topicos/12294525/lei-n-3879-de-25-de-junho-de-2002-do-rio-dejaneiro> Acesso em: 30 maio 2015.

CONSELHO REGIONAL DE ENGENHARIA, ARQUITETURA E AGRONOMIA DO RIO DE JANEIRO (CREARJ). Lista de Verificação - Deficiência Visual. Disponível em: <http://www.acessibilidade.org.br/listaverificacao_acessibilidade_deficiencia_visual.pdf > Acesso em: 06 mai. 2015.

DUARTE, D. C.; BORDA, G. Z.; MOURA, D. G.; SPEZIA, D. S. Turismo acessível no Brasil: um estudo exploratório sobre as políticas públicas e o processo de inclusão das pessoas com deficiência. Revista Brasileira de Pesquisa em Turismo, v.9, p.537 - 553, 2015.

FARIA, M D.; MOTTA, P. C. Pessoas com Deficiência Visual: Barreiras para o lazer turístico. Brasil, 2012.

GUIA DE BOAS PRÁTICAS de Acessibilidade na Hotelaria. Ministério da Economia e do Emprego. Governo de Portugal. Turismo de Portugal. Disponível em:< http://www.turismodeportugal.pt/Portugu\%C3\%AAs/Documents/Guia_boas_praticas_acessibilidad es.pdf> Acesso em 15 jun.2015.

INSTITUTO BRASILEIRO DE GEOGRAFIA E ESTATístICA (IBGE). Censo Demográfico 2000. Brasil, 2000. Disponível em: <http://www.ibge.gov.br/home/presidencia/noticias/27062003censo.shtm> Acesso em: 04 jun. 2015.

INSTITUTO BRASILIEIRO DE GEOGRAFIA E ESTATístICA (IBGE). Censo demográfico 2010 Características Gerais da População, Religião e Pessoas com Deficiência. Brasil, 2010. Disponível em: 
<http://biblioteca.ibge.gov.br/visualizacao/periodicos/94/cd_2010_religiao_deficiencia.pdf> Acesso em: 10 mai. 2015.

MINISTÉRIO DO TURISMO (MTUR). Bem atender do Turismo Acessível. Volume III. Brasil, 2009. Disponível em:

$<$ http://www.turismo.gov.br/turismo/o_ministerio/publicacoes/downloads_publicacoes/VOL UME_III_Bem_atender.pdf> Acesso em: 10 jun. 2015.

MINISTÉRIO DO TURISMO (MTUR). Guia Novos Rumos. Brasil, 2011. Disponível em: $<$ http://www.turismo.gov.br/turismo/o_ministerio/publicacoes/downloads_publicacoes/Guia_No vos_Rumos.pdf> Acesso em: 15 jun. 2015.

MINISTÉRIO DO TURISMO (MTUR). Sistema de Classificação de Meios de Hospedagem. Brasília: Ministério do Turismo, 2010. Disponível em: <http://www.classificacao.turismo.gov.br/MTURclassificacao/mtur- site/downloadCartilha.action?tipo=1> Acesso em: 06 jun. 2015.

OBSERVATÓRIO DO TURISMO DO DISTRITO FEDERAL. Meios de Hospedagem. Disponível em: $<$ http://observatorio.setur.df.gov.br/index.php/meios-de- hospedagem/tradicionais/> Acesso em: 06 mai. 2015.

ORGANIZAÇÃO MUNDIAL DO TURISMO (OMT). Código Mundial de Ética do Turismo. Santiago do Chile, $1999 . \quad$ Disponível em: <http://ethics.unwto.org/sites/all/files/docpdf/portugal.pdf> Acesso em: 16 jun. 2015.

RIBAS, João B. Cintra. O que são pessoas deficientes. Coleção Primeiros Passos. São Paulo: Nova Cultural/Brasiliense, 1985.

SANTIN, Sylvia; SIMMONS, Joyce Nesker. Problemas das crianças portadoras de deficiência visual congênita na construção da realidade. Tradução De Ilza Viegas. Artigo publicado em inglês pela Visual Impairmente and Blindness, 1977.

SECRETARIA DOS DIREITOS DA PESSOA COM DEFICIÊNCIA. Relatório mundial sobre a deficiência / World Health Organization, The World Bank; tradução Lexicus Serviços Lingüísticos. São Paulo: SEDPcD, 2012. Disponível em: <http://www.pessoacomdeficiencia.sp.gov.br/usr/share/documents/RELATORIO_MUNDIAL_COMPL ETO.pdf> Acesso em: 15 jun. 2015.

VAZ, Gil Nuno. Marketing turístico: receptivo e emissivo. São Paulo: Pioneira Thomson Learning, 2002. 